\title{
Transdermal buprenorphine - a critical appraisal of its role in pain management
}

\author{
This article was published in the following Dove Press journal: \\ Journal of Pain Research \\ 14 September 2009 \\ Number of times this article has been viewed
}

\author{
Guy Hans ${ }^{1,2}$ \\ Dominique Robert ${ }^{3}$ \\ 'Multidisciplinary Pain Center, \\ ${ }^{2}$ Department of Anesthesiology, \\ ${ }^{3}$ Department of Critical Care \\ Medicine, Antwerp University \\ Hospital, Edegem, Belgium
}

Correspondence: Guy Hans Multidisciplinary Pain Center (PCT), Antwerp University Hospital (UZA), Wilrijkstraat 10,2650 Edegem, Belgium Tel +3238214945

Fax +3238214586

Email guy.hans@uza.be

\begin{abstract}
This paper reviews the current clinical data for the role of transdermal buprenorphine (BUP TDS) in the treatment of diverse acute and chronic pain syndromes. Literature searches were carried out using PubMed (1988 to June 2009). The published findings seem to support hypotheses regarding the rather unique analgesic mechanisms of buprenorphine as compared with pure $\mu$-opioids like morphine and fentanyl. However, the exact mechanism of this analgesic efficacy still remains largely unknown despite recent advances in preclinical pharmacological studies. Such assessments have demonstrated the sustained antihyperalgesic effect of buprenorphine in diverse animal pain models. These findings are supported in a growing number of clinical studies of oral, intrathecal, intravenous, and BUP TDS. This review paper focuses almost entirely on the clinical experience concerning the transdermal administration of buprenorphine, although preclinical aspects are also addressed in order to provide a complete picture of the unique pharmacological properties of this analgesic drug. Mounting evidence indicates the appropriateness of BUP TDS in the treatment of diverse acute and chronic pain syndromes which have been less or not responsive to other opioids. Additionally, BUP TDS seems to hold great promise for other difficult-to-treat (pain) conditions, such as patients in the intensive care setting. However, its use is somewhat tempered by the occurrence of local skin reactions which have been shown to be often therapy resistant. Further studies are certainly warranted to identify even more precisely the clinical syndromes that are most sensitive to buprenorphine treatment, and to compare buprenorphine to other opioids in head-to-head trials of acute and chronic pain conditions.
\end{abstract}

Keywords: buprenorphine, transdermal, opioids, pain

\section{Introduction}

Buprenorphine, a potent centrally acting opioid analgesic, has been used extensively in clinical practice, and in wide variety of settings for 30 years. ${ }^{1}$ Buprenorphine is an opioid analgesic with a unique physcio-chemical profile. It is a derivative of the morphine alkaloid thebaine. As such, it belongs to the 6, 14-endo-ethanotetrahydroorivavine class of compounds that include other potent $\mu$-agonists such as diprenorphine and etorphine. ${ }^{2}$ Buprenorphine is N-dealkylated to norbuprenorphine mainly in the liver by CYP3A4 and to a lesser extent by CYP2D6, but also by the gut wall, producing the major metabolite norbuprenorphine and several glucuronides of less importance. ${ }^{3}$ CYP3A4 inducers, such as ritanovir, amiodarone, ketoconazole, and erythromycin, but also grapefuit and star-fruit juice, will thereby elevate the serum buprenorphine level. Buprenorphine is eliminated independently of the application route predominantly via the gastrointestinal tract (for almost two-thirds), with the feces containing mainly

submit your manuscript | www.dovepress.com 
unchanged buprenorphine, and only to a lesser extent via the urine (remaining one-third), which contains conjugates of the mother compound and norbuprenorphine. Renal impairment is thus not expected to cause increased plasma accumulation of the mother compound. But renal insufficiency could still lead to an increased plasma concentration of norbuprenorphine as the majority of this metabolite is excreted via the urine. Furthermore, one study showed that hemodialysis did not affect buprenorphine plasma levels, leading to stable analgesic effects during such therapy. ${ }^{4}$ This was proven by the fact that no differences in pain relief before and after hemodialysis could be observed.

Oral administration is a recommended route of delivery for opioid analgesics. However, some opioids are not amenable to oral administration because of extensive first-pas metabolism and poor oral bioavailability. ${ }^{5}$ Furthermore, some oral opioid analgesics, such as propoxyphene, are available only in immediate-release formulations, which require multiple daily doses to maintain around-the-clock pain control in patients suffering from persistent pain. Multiple daily dosing can be inconvenient and may decrease compliance, impair health-related quality of life, and fail to provide sufficient around-the-clock analgesia. ${ }^{6-8}$ Several delivery formulations of buprenorphine have been investigated over the years. The older sublingual and intravenous formulations have been supplemented by a new polymer matrix patch system. ${ }^{9}$ Because it is non-invasive, easily administerd, and has a sustained effect, the transdermal route is beneficial in selected patients, potentially increasing adherence to the analgesic regimen. ${ }^{10,11}$ Transdermal delivery systems (TDS) are an effective method for drug administration in patients with chronic pain. ${ }^{12}$ The TDS allows passive transdermal diffusion of medication over a prolonged period, while maintaining a constant therapeutic dose. The physicochemical properties of buprenorphine (low molecular weight, high lipophilicity, and high affinity for, and slow dissociation from, the $\mu$-opioid receptor) mean it is well suited for transdermal delivery. In this way, problems associated with oral drug formulations, such as poor absorption from the gastrointestinal tract, hepatic first-pass metabolism, and low and variable bioavailability, may be avoided. Thus, transdermal buprenorphine is particularly useful for patients who are not able to swallow properly or who have gastrointestinal disorders or preexisting nausea and vomiting (eg, elderly, patients treated with chemotherapy, patients on intensive care units). There are currently three transdermal buprenorphine preparations (BUP TDS). First, a 3-day patch $\left(\right.$ Transtec $\left.^{\circledR}\right)$, releasing at one of three defined rates: $35 \mu \mathrm{g} / \mathrm{h}, 52.5 \mu \mathrm{g} / \mathrm{h}$, or $70 \mu \mathrm{g} / \mathrm{h}$. Dose effectiveness is reached within 12 to 24 hours, and is kept at a constant dose rate control for 96 hours. In addition, there are low-dose 7-day buprenorphine patches $\left(\right.$ Norspan $\left.^{\circledR}\right)$ which are available in strengths of $5 \mu \mathrm{g} / \mathrm{h}, 10 \mu \mathrm{g} / \mathrm{h}$, or $20 \mu \mathrm{g} / \mathrm{h}$, respectively. Steady state is achieved by day 3 following the first application. After removal of the Norspan transdermal patch, approximately $50 \%$ buprenorphine concentration remains after 12 to 24 hours. In Germany a third transdermal preparation is available, containing a combination of buprenorphine and aloe vera.

Buprenorphine is a molecule that is particularly suited for transdermal delivery because of its high potency, high lipophilicity (octanol-to-water partition coefficient of 1217), and low molecular weight $(467 \mathrm{kDa}) .{ }^{13,14}$ In addition, it is able to achieve good permeability through the dermis and deep tissue layers. Therapeutic efficacy is achieved with daily doses of 0.5 to $2 \mathrm{mg}$, making it 25 to 50 times more potent as an analgesic, per milligram, than morphine. Rather than sitting in a reservoir, buprenorphine is incorporated into an adhesive polymer matrix, with a distinct backing layer of foil that acts as an occluding functioning system.

In recent years, it has become clear that buprenorphine cannot be classified as a typical $\mu$-agonist. Although this review article emphasizes the critical evaluation of the clinical applications of transdermal buprenorphine formulations, it seems essential to start by providing a short overview of the most important pharmacological features of this unique drug. More comprehensive overviews of buprenorphine's pharmacological profile can be found in recent reviews. ${ }^{15-19}$

\section{Buprenorphine: a unique receptor agonist/antagonist}

The complex interaction of a particular opioid with any of the four different opioid receptor types $(\mu, \kappa$, $\delta$, and $\sigma$ ), found both peripherally and centrally, determines the pharmacological effect of an opioid compound. As mentioned earlier, buprenorphine is a semi-synthetic oripavin-derivative of the morphine alkaloid thebain with analgesic potency 25 to 50 times greater than that of morphine..$^{20}$ It binds to $\mu$-, $\kappa-, \delta$-opioid, and nociceptin receptors and has a unique analgesic mechanism of action - one quite different from morphine and fentanyl. ${ }^{21}$ Buprenorphine's potent analgesic effect results from its partial agonist activity at the $\mu$-opioid receptor, and its high affinity for this receptor results in a long duration of action, making it a possible candidate for the effective management of neuropathic pain. ${ }^{22}$ 


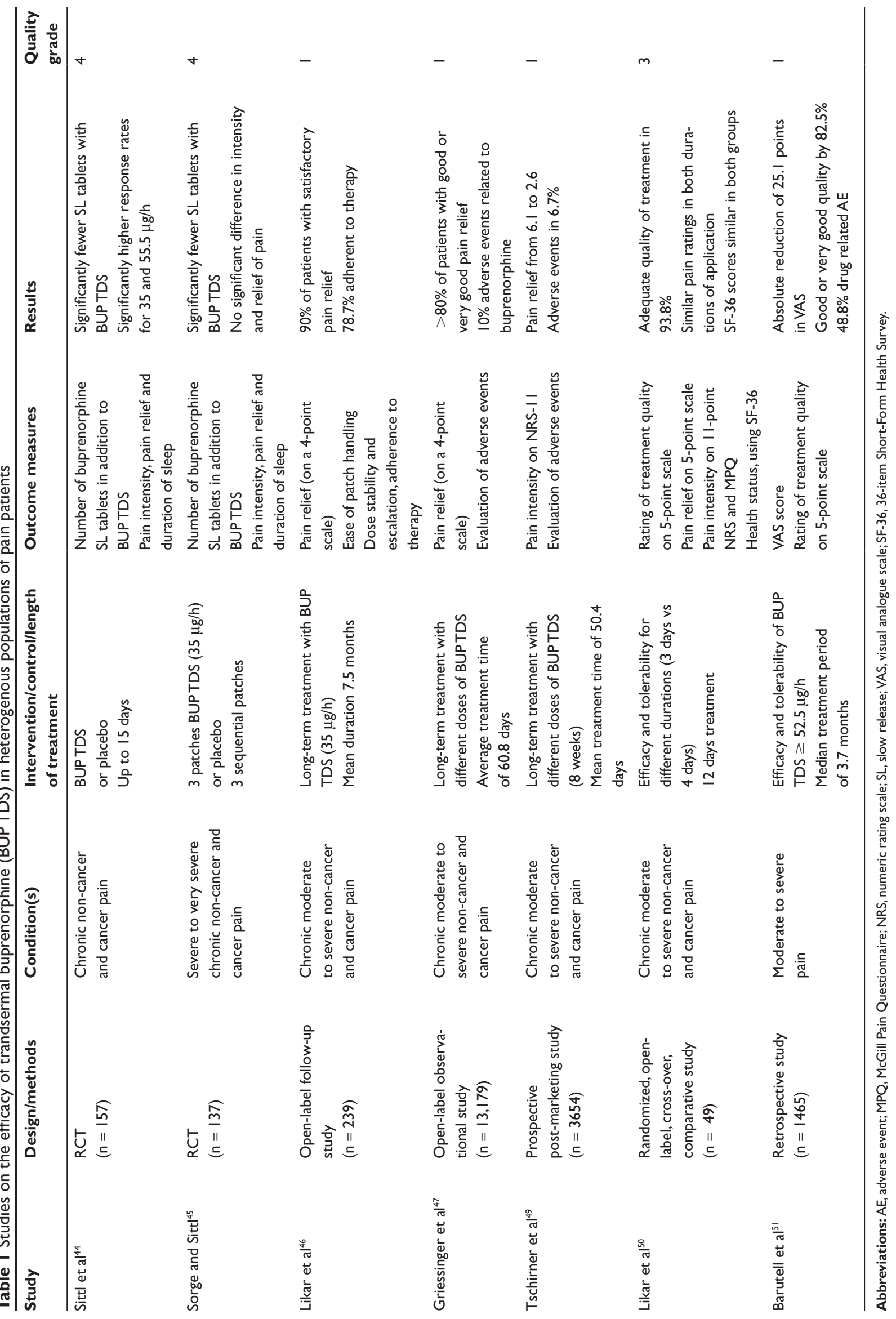




\section{$\kappa_{3}$-opioid receptor antagonist}

In addition to being an antagonist at the $\kappa$ - and $\delta$-opioid receptors, buprenorphine has shown some specific interaction with the $\kappa_{3}$-opioid receptor subtype. ${ }^{23}$ Evidence linking this receptor to neuropathic pain shows that serotonin specific re-uptake inhibitors potentiate $\kappa_{3}$-receptor-mediated analgesia, while having no detectable effect on the $\mu$-receptors. ${ }^{24}$ Furthermore, א-opioid agonists are potent antinociceptive agents against formalin-induced pain - both in neonates and adults - with no antinociceptive effect in the tail flick test. ${ }^{25}$

\section{$\mathrm{K}^{+}$-channel openers}

G-protein-coupled receptor (ie, $\mu$ - and $\delta$-opioid receptor and $\alpha_{2}$-receptor) agonists open specific $\mathrm{K}^{+}$channels in neurons, namely the $\mathrm{K}_{\text {ATP }}{ }^{26,27}$ and the G-protein-gated inward rectifier potassium (GIRK) channels. ${ }^{28}$ Both types of $\mathrm{K}^{+}$channel are involved in opioid-induced antinociception and have been studied extensively.

The opening of $\mathrm{K}_{\text {ATP }}$ channels seems to play an important role in morphine-induced analgesia at supraspinal, spinal, and peripheral levels. While buprenorphine has been shown to open peripheral $\mathrm{K}_{\text {ATP }}$ channels, it also seems to be sensitive to the effects of $\mathrm{K}_{\mathrm{ATP}}$ channel openers and blockers. ${ }^{29}$ Conversely, morphine- and methadone-induced analgesia is only modestly enhanced or attenuated by $\mathrm{K}_{\mathrm{ATP}}$ channel openers and blockers, respectively, and fentanyl exhibits no interactions with $\mathrm{K}_{\text {ATP }}$ agents. This suggests that at least 2 subgroups can be distinguished among $\mu$-opioid receptor agonists, each inducing antinociception through different effector mechanisms. $\mathrm{K}_{\mathrm{ATP}}$ channels represent novel opportunities for enhancing opioid analgesia, particularly in pain syndromes where expression of these ion channels is altered. ${ }^{30,31}$

\section{Nociceptin/orphanin FQ(Noc/OFQ) receptors}

Buprenorphine exhibits a lower (50\% to $70 \%$ ) degree of agonism at the nociceptin receptor compared with the endogenous ligand nociceptin, which leads to antinociception via opioid receptor-like receptor-1 (ORL-1)-mediated mechanisms, particularly at high doses. ${ }^{32-35}$ Following systemic administration of buprenorphine, this analgesic effect can be countered by simultaneous activation of supraspinal ORL-1 receptors. ${ }^{36}$ Conversely, sole activation of spinal ORL-1 receptors by buprenorphine may lead to an important antinociceptive effect, which might explain the strong analgesic action observed after intrathecal administration of buprenorphine; $; 7-40$ however, some evidence suggests a supraspinal site of action after neuraxial administration. ${ }^{41,42}$ Overall, the clinical result following administration of buprenorphine, by whichever route, is dose-related analgesia and, therefore, the precise involvement of the ORL-1 receptor remains unclear. ${ }^{18}$

\section{Review methodology}

A systematic and extensive literature search was carried out using the PubMed database (from 1988 to June 2009). The search terms included 'buprenorphine' and 'transdermal', as well as 'nociceptive pain', 'neuropathic pain', 'acute pain', 'chronic pain', 'hyperalgesia', and 'allodynia'. To our knowledge this review includes almost all of the available information on the subject of transdermal buprenorphine and pain. The data consist of double-blind, randomized controlled trials (RCTs), open-label studies, retrospective analyses, observational studies, two post-marketing surveillance (PMS) studies, a number of case studies, as well as some very recent high-quality reviews on buprenorphin. Some cases of abuse of intravenous buprenorphine, as well as publications on sublingual administration of buprenorphine, have been excluded as they are irrelevant to the subject of this review. The Oxford quality scoring system, better known as the Jadad scale, was applied to assess independently the methodological quality of the included trials. ${ }^{43}$ It was however not the intention of the authors to create a meta-analysis of all of the published studies on BUP TDS.

\section{Transdermal buprenorphine: clinical efficacy}

Published results from a growing number of clinical studies demonstrate the interesting analgesic profile of buprenorphine in the treatment of diverse pain conditions, often previously unresponsive to opioid therapy. Studies are hereby reviewed rather in order of their clinical significance.

Two RCTs have previously assessed the effectiveness of BUP TDS for the management of chronic cancer and non-cancer pain (see Table 1 for methodological overview and quality grading). One of these multicenter RCTs demonstrated the potential analgesic efficacy and tolerability of BUP TDS in patients with chronic pain. ${ }^{44}$ In this study of 157 patients, BUP TDS (35 and $52.5 \mu \mathrm{g} / \mathrm{h}$ ) was associated with a significantly higher response rate compared with placebo $(36.6 \%[P<0.05]$ and $47.5 \%[P<0.005]$, respectively). A notable, but not significant, improvement in response (33\%) was seen with the $70 \mu \mathrm{g} / \mathrm{h}$ dose. Administration of BUP TDS significantly reduced $(56.7 \% ; P<0.005)$ administration of sublingual buprenorphine rescue analgesia compared with placebo. The improvement in quality of sleep, in addition to the good tolerability profile and reduced need 
for rescue analgesia, suggest BUP TDS is beneficial for the treatment of diverse chronic pain states. In addition, this study indicated no difference in efficacy of BUP TDS between neuropathic and non-neuropathic pain conditions.

In the second double-blind RCT, 137 patients were randomized to receive BUP TDS patches (72 hours) or placebo. ${ }^{45}$ Rescue therapy in both groups was sublingual buprenorphine. Ninety patients received buprenorphine and 47 were treated with placebo patches. Forty-five patients had cancer pain and 92 had non-cancer pain. Patients receiving BUP TDS significantly reduced their consumption of sublingual buprenorphine compared with the control group $(P=0.03)$. Patients' assessment of pain intensity and relief suggested better analgesia with BUP TDS, although these results never gained statistical significance during the study protocol $(P>0.05)$.

A total of 239 patients from the previously described RCTs participated subsequently in an open label follow-up study, which demonstrated that BUP TDS was effective in controlling chronic pain over a long period, without the need of significant dose increases (lack of tolerance development). ${ }^{46}$ The maximum study participation was 3.4 years in cancer patients $(n=134)$, and 5.7 years in non-cancer patients $(n=105)$. In total, $90 \%$ of patients reported at least satisfactory pain relief, measured using a 4-point verbal scale. Moreover, BUP TDS was generally well tolerated during long-term treatment both in cancer and non-cancer patients, with the most common side effects being nausea $(9.2 \%)$, dizziness $(4.6 \%)$, vomiting $(4.2 \%)$, constipation (3.8\%), and tiredness (2.9\%). Local adverse reactions with BUP TDS included erythema (12.1\%), pruritus (10.5\%), and exanthema $(8.8 \%)$. This study provided some highly interesting clinical findings, since the results indicate the absence of development of tolerance during longer periods of treatment. In addition, incidence of side effects remained low during the prolonged treatment.

Similar results were observed during a large-scale PMS study of 13,179 patients with moderate-to-severe chronic cancer $(25 \%)$ or non-cancer $(72 \%)$ pain. The effectiveness and tolerability of BUP TDS were assessed over an average treatment time of 60.8 days. ${ }^{47}$ The most frequent diagnoses in non-cancer patients were musculoskeletal disorders (77\%) and neuropathy $(23 \%)$, and the majority of patients were treated with BUP TDS $35 \mu \mathrm{g} / \mathrm{h}$. In total, $80 \%$ of patients reported good or very good pain relief with BUP TDS at the final assessment (median time 63 days), compared with only $6 \%$ at the start of the study. Good or very good pain relief was achieved in $84 \%$ of cancer patients and $80 \%$ of non-cancer patients. At the end of the study, only $4 \%$ of cancer patients and $6 \%$ of non-cancer patients reported poor or no pain relief. This study also revealed that the overall incidence of both systemic and local side effects is lower in clinical practice compared with clinical studies. Patients reported vomiting $(1.6 \%)$, nausea $(4 \%)$, constipation $(1 \%)$, pruritus $(0.7 \%)$, erythema $(0.5 \%)$, and contact dermatitis $(0.8 \%)$. Moreover, compared with PMS data of fentanyl transdermal patch (FEN TDS), long-term use of BUP TDS resulted in a lower incidence of CNS side effects. ${ }^{47,48}$

A more recent, but somewhat smaller, prospective multicenter PMS study obtained comparable results. ${ }^{49}$ This study was aimed at obtaining information on the efficacy, tolerability and safety of a transdermal buprenorphine patch in patients with moderate to severe chronic (cancer and noncancer) pain. In addition it was evaluated to what extent a two fixed patch change days per week were simplifying the therapy. The evaluation included pain intensity, the dosage of the applied analgesics and additional therapies, the renal function (by serum creatinine) and adverse events. A total of 3654 patients were treated for a mean of 50.4 days. Using the 11-point Likert-scale the mean pain intensity decreased from 6.3 at the time when patients were switched to the BUP TDS to 2.6 at the last treatment evaluation. The matrix patch was safe and well tolerated also in patients with advanced renal insufficiency. Adverse events were reported in $6.7 \%$ of the patients. Most $(89.3 \%)$ of the physicians stated a preference for transdermal buprenorphine with the two fixed patch change days per week compared to the pre-treatment. From the physicians' view the two fixed patch change days per week even facilitated the guidance of therapy.

For this application regimen, Likar et al even investigated the possibility of a 4-day instead of the usual 3-day regimen. ${ }^{50}$ The primary recommendation contained in the prescribing information is that transdermal patches be worn for a 3-day period before application of a new patch. This single-center, randomized, open-label, crossover Phase III study was therefore conducted to evaluate the potential for extending the time the buprenorphine patch is worn from 3 to 4 days. Patients suffering from chronic moderate or severe pain of malignant or non-malignant origin were included. Study participants had already responded to at least 4 weeks of BUP TDS, and had achieved steady-state conditions for at least 2 weeks before enrollment. The primary endpoint was patients' rating of the quality of treatment (analgesic efficacy and tolerability, rated on a 5-point scale: very good, good, satisfactory, poor, and inadequate) at the completion of each treatment regimen (12 days each). Also recorded were physicians' ratings of 
Table 2 Studies on the efficacy of trandsermal buprenorphine (BUPTDS) in neuropathic pain

\begin{tabular}{|c|c|c|c|c|c|c|}
\hline Study & Design/methods & Condition(s) & $\begin{array}{l}\text { Intervention/control/ } \\
\text { length of treatment }\end{array}$ & $\begin{array}{l}\text { Outcome } \\
\text { measures }\end{array}$ & Results & $\begin{array}{l}\text { Quality } \\
\text { grade }\end{array}$ \\
\hline Rodriguez-Lopez ${ }^{52}$ & $\begin{array}{l}\text { Retrospective study } \\
(n=237)\end{array}$ & $\begin{array}{l}\text { Non-malignant } \\
\text { neuropathic pain }\end{array}$ & $\begin{array}{l}\text { Efficacy and tolerability } \\
\text { of BUPTDS } 35 \text { and } 52.5 \mu \mathrm{g} / \mathrm{h} \\
\text { Treatment period of } 8 \text { weeks }\end{array}$ & $\begin{array}{l}\text { VAS score } \\
\text { Sleep score }\end{array}$ & $\begin{array}{l}55 \% \text { reduction in VAS } \\
\text { score } \\
\text { Significant improvement } \\
\text { in sleep score }\end{array}$ & I \\
\hline Penza et $\mathrm{a}^{53}$ & $\begin{array}{l}\text { Open-label study } \\
(n=30)\end{array}$ & $\begin{array}{l}\text { Chronic painful } \\
\text { neuropathy } \\
\text { ( } \geq 5 \text { on VAS) }\end{array}$ & $\begin{array}{l}\text { Efficacy and tolerability of } \\
\text { increasing doses of BUPTDS } \\
\text { Treatment period of } 42 \text { days }\end{array}$ & $\begin{array}{l}\text { Number of patients } \\
\text { achieving at least } \\
30 \% \text { pain reduction } \\
\text { at day } 42\end{array}$ & $\begin{array}{l}13 / 30 \text { achieved } 30 \% \\
\text { reduction } \\
9 / 30 \text { drop-outs, and } 8 / 30 \\
\text { failed to reach outcome }\end{array}$ & I \\
\hline
\end{tabular}

Abbreviation: VAS, visual analogue scale.

the quality of treatment; pain intensity, rated on an 11-point numerical rating scale (from $0=$ no pain to $10=$ worst pain imaginable) and on the McGill Pain Questionnaire (MPQ) (maximum pain $=3.0$ ); health status, assessed using the 36-item Short-Form Health Survey (SF-36), expressed as a percentage of the best health condition (100\%); and pain relief (5-point scale: complete, good, satisfactory, slight, and none). Local skin tolerability was evaluated for objective and subjective dermatologic symptoms at the patch application sites. Patients recorded daily pain intensities at specified times of day and night, pain relief (5-point verbal rating scale), and sleep duration ( $\leq 2$ hours, $>2$ to 3 hours, $>3$ to $<6$ hours, or $\geq 6$ hours) in a diary. The safety profile was evaluated based on standard monitoring of adverse events, vital signs, and routine laboratory tests. Forty-nine white patients (25 women, 24 men) were enrolled; their mean (SD) age was 61.6 (11.5) years, and their mean weight was 74.7 (16.7) $\mathrm{kg}$. The most common source of pain was musculoskeletal disorders (40 patients), followed by nervous system disorders (10), neoplasms (9), injuries (5), and other causes (6). Forty-one patients completed the study; 2 patients discontinued because of adverse events, 1 because of lack of efficacy, and 5 for non-medical reasons. Thirty-three patients provided data per protocol. Patients in the perprotocol population received a mean (SD) transdermal buprenorphine dose of $49.9(38.9) \mu \mathrm{g} / \mathrm{h}$. The proportion of patients in the per-protocol population rating the quality of treatment as adequate (combined ratings of very good, good, and satisfactory) was $93.9 \%$ (31/33) for both regimens. The physicians' ratings indicated adequate quality of treatment in $93.8 \%$ (30/32) of patients applying 4 patches for 3 days each and 97.0\% (32/33) of patients applying 3 patches for 4 days each. Mean (SD) pain intensity scores on the numerical rating scale were similar after completion of the 3- and 4-day regimens (3.73 [1.88] and 3.88 [1.75] points, respectively), as were MPQ scores (0.79 [0.67] and $0.79[0.78])$. The mean (SD) proportion of days with at least satisfactory pain relief was $83.9 \%$ (26.1\%) and $85.6 \%$ (24.4\%) for the 3- and 4-day regimens; the corresponding proportions of nights with at least satisfactory pain relief were $85.2 \%(26.6 \%)$ and $88.1 \%(21.4 \%)$. Continuously assessed pain intensities at specified times of day and night (numerical rating scale) did not differ significantly between regimens. Mean SF-36 health status scores did not differ significantly between regimens (total score: 37.7\% [17.0\%] and 37.7\% [17.3\%]). Mean rates of nights with good sleep quality were $28.5 \%(39.9 \%)$ for the 3 -day regimen and $36.0 \%$ (42.6\%) for the 4-day regimen. Local skin tolerability was comparable for the 3- and 4-day regimens, with objective findings (mainly erythema) at the patch-application sites in 17 of 32 and 11 of 33 patients, respectively, and subjective symptoms (mainly itching) in 16 of 32 and 13 of 33 patients. The most common adverse events in the safety population were nausea, dizziness/giddiness, and malaise/fatigue (3/49 [6.1\%] each). On the basis of the above-mentioned results ${ }^{49,50}$ we currently recommend our patients to apply the buprenorphine patches during 3.5 days, resulting in 2 fixed patch change days per week (eg, on Monday morning and Thursday evening).

Spanish pain centers recently completed a retrospective multicenter safety and efficacy study, assessing the effectiveness of BUP TDS in a large number of patients $(n=1465)$ suffering from moderate to severe pain. ${ }^{51}$ Pain could have any etiology. All patients suffered from pain $\geq 50 \mathrm{~mm}$ on a 0 to $100 \mathrm{~mm}$ visual analog scale (VAS) and were switched to BUP TDS receiving a dose of $\geq 52.5 \mu \mathrm{g} / \mathrm{h}$ for at least 14 days during the previous months. An absolute reduction of 25.1 points in VAS score was observed over a median period of 3.7 months. In addition, the VAS score was reduced by at least $10 \%$ in $88.4 \%$ of the patients. Incidence of episodic pain also decreased significantly. Most (82.5\%) patients rated this treatment as "good" or "very good". Of all patients, $50.2 \%$ experienced an adverse event, which in $48.8 \%$ was drug-related, and considered serious in $4.0 \%$. 
While the aforementioned studies assessed the efficacy of buprenorphine in a heterogenous group of pain conditions, additional studies and reports specifically focused on painful neuropathic syndromes (see Table 2 for an overview of these studies and quality grading). A retrospective study across 20 pain management centers assessed the effectiveness of BUPTDS (35 and $52.5 \mu \mathrm{g} / \mathrm{h}$ ), over an 8-week period, in a total of 237 patients suffering from non-malignant neuropathic pain. ${ }^{52}$ Tramadol (75 to $110 \mathrm{mg} /$ day) was provided for the treatment of breakthrough pain. Significant improvements in VAS scores $(P<0.001)$ were achieved at all endpoints compared with baseline, a 55\% reduction in mean VAS pain scores being achieved by week 8 . Improvements were most notable in those symptoms rated 'severe' at baseline. Significant improvements $(P<0.001)$ in sleep scores provided additional support for the clinical effectiveness of BUP TDS, with increases from $4.9( \pm 1.5)$ hours to $6.2( \pm 1.39)$ hours. Finally, it was shown that buprenorphine TDS had a good safety and high user compliance profile, which improved even further over the course of the treatment.

A very recent open-label study investigated the efficacy, safety, and tolerability of BUP TDS in 30 patients suffering from moderate to severe chronic painful neuropathies (VAS $\geq 5$ ). ${ }^{53}$ Starting doses of $35 \mu \mathrm{g} / \mathrm{h}$ were increased in case of unsatisfactory pain control. Primary endpoint was the number of patients achieving at least $30 \%$ pain relief at day 42 (in order to evaluate short- and intermediate-term efficacy). Finally, 13 patients achieved this endpoint. Nine patients dropped out for side effects, and 8 patients did not meet the primary outcome. These results seem to indicate that BUP TDS induces clinically meaningful pain relief in about $40 \%$ of the patients suffering from chronic painful neuropathies.

Although of much more limited scientific value, patient case reports often provide a valuable insight into pain management in daily clinical practice. The efficacy of BUP TDS in the treatment of nerve-injury-induced pain is further demonstrated in case reports presented by Likar and Sittl. ${ }^{54}$ Two patients with neuropathic pain, and two patients with nociceptive pain with a neuropathic component, experienced well-tolerated and prolonged pain relief, and fewer episodes of breakthrough pain with BUP TDS compared with FEN TDS. The patients switched from other opioids to buprenorphine without adverse effects and required a lower level of buprenorphine to match the level of analgesia achieved with previous opioids $(70 \%)$.

Other studies have been focusing on the treatment of cancer pain (see Table 3 for an overview of these studies and quality grading). A company-sponsored study has investigated the efficacy and safety of BUP TDS in patients suffering from severe cancer pain..$^{55}$ Two hundred eighty-nine cancer patients were included in a randomized, placebo-controlled, study with an enriched design, making this study the largest placebo-controlled study ever performed in patients with cancer. Treatment with BUP TDS $70 \mu \mathrm{g} / \mathrm{h}$ was compared to placebo in opioid-tolerant cancer patients requiring strong opioid in a dose range of 90 to $150 \mathrm{mg} / \mathrm{d}$ oral morphine equivalents. All patients first entered a run-in phase during which they were converted to BUP TDS. Those patients who could be stabilized on BUP TDS were then randomized to transdermal buprenorphine patches or placebo patches for a 2-week maintenance phase. Hundred patients discontinued treatment during the run-in phase due to lack of efficacy or adverse events, while 189 patients continued treatment in the maintenance phase (94 BUP TDS vs 95 placebo). Of these, 31 discontinued treatment, a vast majority of whom came from the placebo treatment group (24 vs 7 BUP TDS). A significantly higher number of patients responded well to the treatment in the buprenorphine group versus the placebo group ( $74.5 \%$ vs $50 \%, P=0.0003$ ). These responder results were further supported by lower daily pain intensities, lower intake of rescue medication (buprenorphine sublingual tablets) and lower dropout rates in the BUP TDS group. It should be noted that even during the run-in period, the mean daily pain intensity and the mean daily intake of rescue medication both decreased in $70 \%$ of patients during the first 12 hours following active patch application, indicating a rapidly developing distinct analgesic response from BUP TDS.

An open PMS study conducted in Spain enrolled 1223 patients (male and female, mean age 64.6 years), 207 (18\%) of whom had recorded chronic moderate-to-severe cancer pain that had not responded to non-opioid analgesics. ${ }^{56}$ BUP TDS $35 \mu \mathrm{g} / \mathrm{h}$ was used to treat the majority of patients (89\%). After 3 months, the $35 \mu \mathrm{g} / \mathrm{h}$ patch was still being used by $52 \%$ of patients, and they were satisfied with the pain relief provided. Pain relief was reported as very good or good in $89 \%$ of patients, increasing from $5 \%$ prior to the start of the study. Another open, multicenter, retrospective, pharmacoepidemiological study was performed by the same principal author and used data collected from 164 patients (average age $64.3 \pm 12$ years) with moderate-to-severe cancer pain attending pain centers throughout Spain. ${ }^{57}$ The majority of patients continued with low doses of BUP TDS ( 35 or $52.5 \mu \mathrm{g} / \mathrm{h}$ ) until the end of the study. At baseline $84 \%$ of patients reported a pain score of 7 . After 2 weeks, $41 \%$ of patients reported a pain score of $<4$, rising to $76 \%$ after 8 weeks. 


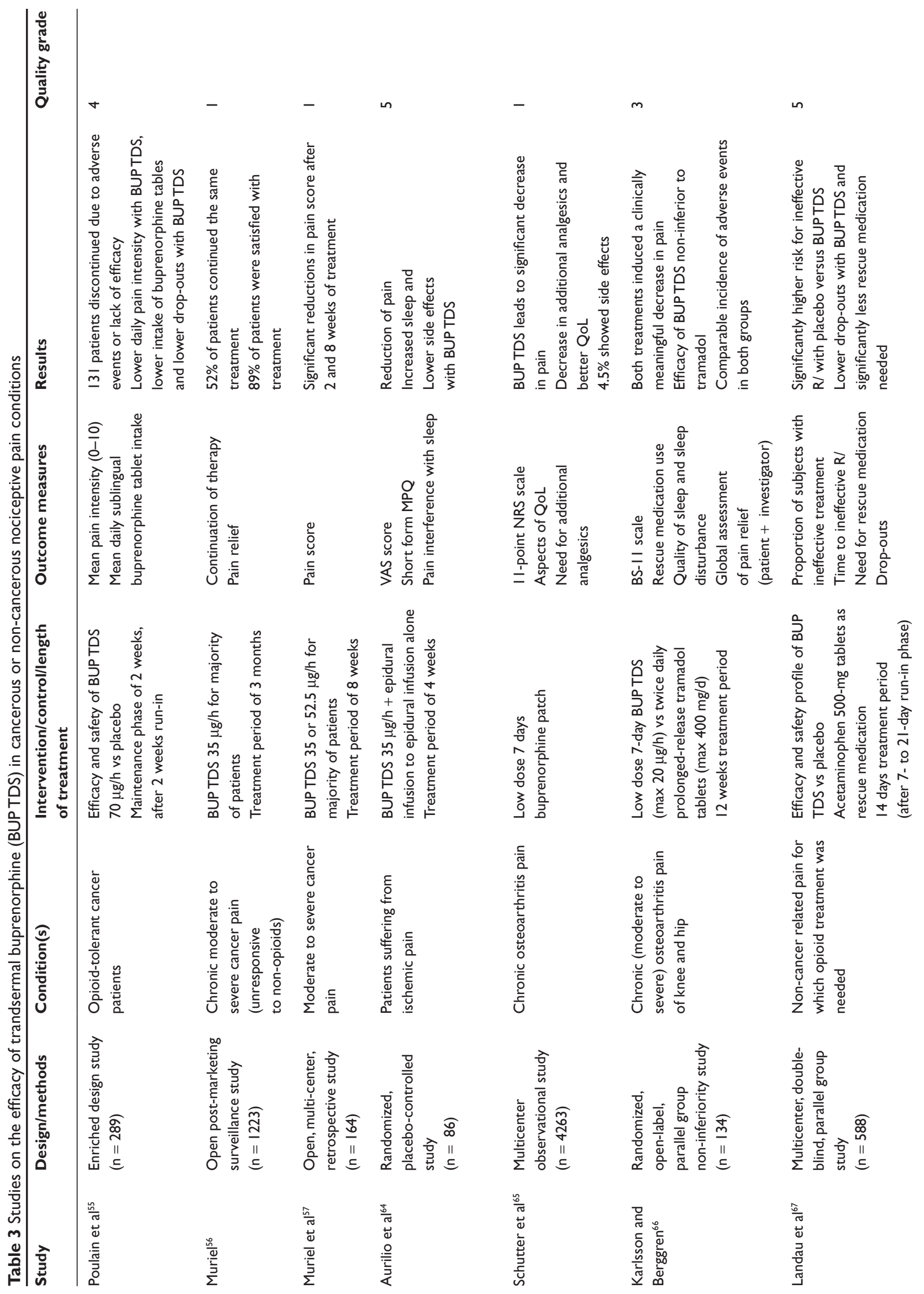


Lately, the first reports have been emerging on the effective use of BUP TDS in young children (aged 3 to 5 years) suffering from cancer pain. ${ }^{58}$ In all cases distinct decreases in pain scores were observed, with reduction of the overall amount of medications (especially opioids) and improvement of uninterrupted sleep. Although only limited data are available on the use of BUP TDS in children, these cases indicate that BUP TDS could allow good analgesia without significant side effects in children suffering from severe cancer-related pain.

Recently the findings of an expert panel consensus were published on the role of BUP TDS in the treatment of cancer pain. ${ }^{59}$ The consensus was that BUP TDS has a valuable role to play in the treatment of chronic cancer pain because of its efficacy and good safety and tolerability profile, including a low risk of respiratory depression, a lack of immunosuppression, and a lack of accumulation in patients with impaired renal function. The registered dose range of 35 to $140 \mu \mathrm{g} / \mathrm{h}$ was considered adequate to achieve sufficient pain relief in most patients, although some members of the panel presented data showing that increases beyond this dose range provided improved pain relief if slow titration is used. However, it was generally felt that more evidence was needed before this could become generally acceptable. Nevertheless, a number of general recommendations were made. Large-scale, randomized clinical studies are needed to provide product comparisons on the use of analgesics in the treatment of neuropathic pain, although it was recognized that such studies may not be practicable. Physicians should be made more aware of the problem of hyperalgesic effects of some opioids in long term use. Buprenorphine in contrast has been described to exert an antihyperalgesic effect. ${ }^{60}$ The development of analgesic tolerance with some opioids in long-term use and the lack of it with buprenorphine requires further studies.

Finally, in contrast to older beliefs that the use of buprenorphine would prevent future use of opioids (due to an irreversible and permanent blocking of opioid receptors), it has been shown that use of BUP TDS in cancer patients does not impede them from future opioid therapies. ${ }^{61}$ The aim of this study was to confirm that the concomitant presence of FEN TDS and BUP TDS may be feasible without important consequences, using doses presumed to be equianalgesic. A prospective " $\mathrm{N}$ of 1 " study was carried out in a sample of volunteers with cancer pain receiving stable doses of FEN TDS or BUP TDS, with adequate pain and symptom control. In the study design, each patient provided data before and after a switch from one opioid to the other and then back 
to the previous one. Sixteen patients receiving daily stable doses of 0.6 or $1.2 \mathrm{mg}$ of FEN TDS were switched to BUP TDS using an FEN-BUP ratio of 0.6 to 0.8 . After 3 days, the buprenorphine patch was removed and a fentanyl patch was placed for another 3 days. Six patients receiving buprenorphine were switched to FEN TDS and then rotated back to BUP TDS with the same dosing considerations. No statistical differences in changes in pain and symptom intensity during switching and between the two different sequences were observed. No significant changes in rescue doses of oral morphine were reported at the same intervals. These results clearly indicate that cancer patients receiving stable doses of transdermal fentanyl or buprenorphine can be safely switched to an alternative transdermal opioid. Safe and efficacious opioid rotation from high-dose morphine to BUP TDS has also been demonstrated in different types (musculo-skeletal, cancer, and neuropathic) of severe chronic pain. ${ }^{62}$ A final study assessed the efficacy and tolerability of an alternative transdermally applied opioid (either fentanyl or buprenorphine) in 32 patients with chronic cancer pain receiving insufficient analgesia using their present treatment. ${ }^{63}$ Sixteen were switched from FEN TDS to BUP TDS (75 $\mu \mathrm{g} / \mathrm{h}$ fentanyl converted to $52.5 \mu \mathrm{g} / \mathrm{h}$ buprenorphine), and 16 from BUP TDS to FEN TDS (70 $\mu \mathrm{g} / \mathrm{h}$ buprenrophine converted to $25 \mu \mathrm{g} / \mathrm{h}$ of fentanyl). The dosage used was $50 \%$ of that indicated in equipotency tables. Pain relief was assessed at weekly intervals for the next 3 weeks. There was no significant difference in either pain relief or rescue medication use between the two patient groups. The number of patients with adverse events decreased during the study. These results clearly indicate that opioid switching at $50 \%$ of the calculated equianalgesic dose significantly reduces pain levels and rescue medication.

Other studies have been examining the efficacy of BUP TDS in different types of chronic, non-cancer, pain. One recent randomized study investigated the efficacy of BUP TDS as add-on therapy in the treatment of ischemic pain. ${ }^{64}$ This is an interesting protocol from a clinical standpoint since ischemic pain is generally considered as difficult to treat and often unresponsive to (strong) analgesics. Eighty-six patients were randomized in 2 groups. In the first group, a $35 \mu \mathrm{g} / \mathrm{h}$ BUP TDS was applied and an additional peridural infusion of ropivacaine/morphine (200 mg $+2 \mathrm{mg}$ ) was established. In the second group, an identical ropivacaine and morphine epidural analgesia was obtained but a placebo patch was added on top. VAS for pain was used as the primary efficacy parameter. In addition, short-form MPQ scores and a score for pain interference with sleep were obtained from the patients every week for a period of 4 weeks. The subjects in the BUP TDS group reported a significant reduction in pain, increased sleep, and even a lower incidence of side effects compared with the control group (all $P<0.05$ ).

The efficacy and safety of the 7-day low-dose buprenorphine matrix patch was recently evaluated in routine clinical practice in a multicenter observational study in 4263 patients with chronic osteoarthritis pain. ${ }^{65}$ During treatment a significant decrease in mean pain could be observed ( 6.9 before treatment to 2.9 on a 11-point scale at the end of the observation period). Furthermore, the investigators observed a decrease in additional analgesic medication and improvements in mobility and quality of sleep. Only $4.5 \%$ of the patients displayed adverse effects, making BUP TDS a safe way of chronic pain relief for osteoarthritis patients.

In a similar patient population (chronic osteoarthritis pain of the hip and knee) the efficacy and safety of low dose $(5,10$, and $20 \mu \mathrm{g} / \mathrm{h})$ BUP TDS was compared to prolongedrelease tramadol tablets. ${ }^{66}$ Eligible patients were adults with a clinical and radiologic diagnosis of osteoarthritis (OA) and moderate to severe pain, while using paracetamol $4000 \mathrm{mg} / \mathrm{d}$ for pain during the screening week. Patients were randomized in a 1:1 ratio to receive either low-dose 7-day buprenorphine patches (patch strengths of 5, 10, and $20 \mu \mathrm{g} / \mathrm{h}$, with a maximum dosage of $20 \mu \mathrm{g} / \mathrm{h}$ ) or twice-daily prolonged-release tramadol tablets (tablet strengths of 75 , 100,150 , and $200 \mathrm{mg}$, with a maximum dosage of $400 \mathrm{mg} / \mathrm{d}$ ) over a 12-week open-label treatment period. Supplementary paracetamol was available as rescue medication throughout the study. The primary endpoint was the difference in BS-11 scores from baseline to the completion of treatment (non-inferiority was assumed if the treatment difference on the BS-11 scale was -1.5 boxes). Secondary efficacy variables were rescue medication use, sleep disturbance and quality of sleep, and patients' and investigators' global assessments of pain relief. One hundred thirty-four patients (69 receiving 7-day buprenorphine patches and 65 receiving tramadol tablets) were randomized and received $\geq 1$ dose of study medication. Of the 2 treatment groups $98.6 \%$ and $100 \%$ were white, respectively, with mean (SD) ages of 64.4 (11.1) and 64.2 (9.3) years. Both treatments were associated with a clinically meaningful reduction in pain from baseline to study completion. The least squares mean change from baseline in BS-11 scores in the 7-day buprenorphine patch and tramadol tablet groups were $-2.26(95 \% \mathrm{CI},-2.76$ to -1.76$)$ and $-2.09(95 \% \mathrm{CI},-2.61$ to -1.58$)$. The efficacy of 7-day buprenorphine patches was non-inferior to that 
of prolonged-release tramadol tablets. The incidence of adverse events (AEs) was comparable in the 2 treatment groups: 226 AEs were reported in 61 patients (88.4\%) in the 7-day buprenorphine patch group, and 152 AEs were reported in 51 patients $(78.5 \%)$ in the tramadol group. The most common AEs in the 7-day buprenorphine patch group were nausea $(30.4 \%)$, constipation $(18.8 \%)$, and dizziness (15.9\%); the most common AEs in the tramadol tablet group were nausea $(24.6 \%)$, and fatigue $(18.5 \%)$. Most patients (47/67 [70.1\%] in the 7-day buprenorphine patch group and 43/61 [70.5\%] in the tramadol tablet group) reported that they would prefer a 7-day patch to a twice-daily tablet for future pain treatment. It can therefore be concluded that in patients with chronic, moderate to severe OA pain of the hip and/or knee, 7-day low-dose buprenorphine patches is an effective and well-tolerated analgesic which is non-inferior to prolonged-release tramadol tablets.

Another multicenter, double-blind, parallel-group study compared the efficacy of buprenorphine transdermal 7-day patches and placebo in subjects with persistent non-cancer pain who required opioid analgesics. ${ }^{67}$ Adult subjects (588) with at least a 2-month history of non-cancer-related pain for which they received oral opioid combination agents entered the open-label run-in phase. Subsequently 267 were randomized to the double-blind treatment (129 BUP TDS, 138 placebo). The primary efficacy variable was the proportion of subjects with ineffective treatment during the double-blind evaluation phase. The secondary efficacy variables were the time to ineffective treatment or patients who discontinued for reasons other than ineffective treatment and use of escape medication. The results clearly indicated that the odds of ineffective treatment were 1.79 times greater for placebo than for BUP TDS $(P=0.022)$. Other indicators of effective treatment, such as discontinuation for reason of ineffective therapy, showed also significantly higher results in the buprenorphine treated patient population. The mean amount of escape medication was significantly lower in the BUP TDS group than in the placebo group (1.7 vs 2.2 acetaminophen tables per day, $P=0.015)$. A limitation of this study is that it did not incorporate direct validated measures of pain control, such as the VAS.

An interesting study compared the analgesic efficacy and tolerability of BUP TDS in patients over and under 65 years of age. ${ }^{68}$ A group of elderly were hereby compared to 2 younger equally sized populations, all requiring analgesic treatment for moderate to severe chronic pain of diverse etiology. During the 28-day treatment period potential differences in responsiveness (pain intensity, rescue medication, and sleep duration) were observed. Two-thirds of the patients completed the study, with similar rates and reasons for premature study termination in all age-groups. Pain intensities significantly decreased from pretreatment until the end of the study without differences between age-groups. At the end of the study period daily mean pain intensities were even significantly lower in elderly patients as compared with both younger age-groups. In addition, need for rescue medication was the lowest in elderly patients. Most prominent side effects were dizziness, nausea, and local skin tolerability issues, with comparable percentages in all groups. This study clearly indicated that BUP TDS treatment in elderly patients above the age of 65 years is at least as effective, tolerable, and safe as in younger patients. With the increasing age of patients suffering from pain, the results of this study will undoubtly have an important clinical impact in the future. In fact, this good tolerability of BUP TDS in the elderly has recently been confirmed by a consensus statement report. ${ }^{69}$ Its advantages in the elderly have also thoroughly been described in a recent review paper. ${ }^{70}$

\section{Equi-analgesic ratio between buprenorphine and other opioids}

A clinically very relevant, yet difficult to answer question, concerns the equianalgesic ratio of BUP TDS compared to other opioids like oral morphine, oral oxycodone, and FEN TDS. The equipotency ratio of FEN TDS to oral morphine has been established as 1:100; for BUP TDS, a ratio of 1:75 has been proposed, although this ratio has never been confirmed in clinical studies. Growing evidence from clinical practice, in which much lower doses of buprenorphine are used, suggests that this conversion ratio may be too high. For a long period BUP TDS was not even included in most of the published conversion tables. However, a recent study shed some interesting new light on this discussion, investigating the equianalgesic ratio in a population of cancer patients. ${ }^{71}$ A sample of consecutive patients $(n=11)$ receiving stable doses of 120 to $140 \mathrm{mg}$ of oral morphine or 50 to $100 \mu \mathrm{g}$ of FEN TDS and who reported adequate pain and symptom control, were included in this protocol. The authors identified a ratio of 70:1 for oral morphine and 0.6:0.8 for FEN TDS. No significant changes in pain and symptom intensity were found, except significant improvement in reported constipation $(P=0.014)$. Global satisfaction with the analgesic treatment also increased significantly after conversion. Similar findings were obtained in the previously mentioned study by Aurilio et al, in which switching between FEN TDS and BUP TDS at $50 \%$ of the 
calculated equianalgesic dose was shown to significantly reduce pain and need for rescue medication. ${ }^{63}$

Additional interesting information was obtained from a study by Wirz et al. ${ }^{72}$ Although the purpose of this trial was to evaluate the effect of long-term treatment with different opioid formulations on nausea, emesis, and constipation, the authors also evaluated the morphine equivalent opioid doses. These morphine-equivalent opioid doses differed significantly (mg/d FEN TDS: 183; BUP TDS: 89; oral hydromorphone: $143 ; P=0.001$ ), because of obvious tolerance varying after long-term treatment. The authors concluded that conversion ratios for transdermal fentanyl, transdermal buprenorphine, and oral hydromorphone did not accord with those previously published, because of differing occurrences of opioid tolerance after long-term therapy.

A third study did also focus on the equipotent doses between FEN TDS and BUP TDS. ${ }^{73}$ The aim of this retrospective study was to compare calculated equipotent oral morphine doses of FEN TDS with equipotent oral morphine doses of BUP TDS prescribed in clinical practice. Patients with cancer and non-cancer pain who had received $\geq 1$ prescription for FEN TDS or BUP TDS (the all-patients groups) were identified from the German IMS Disease Analyzer-mediplus database, which contains all relevant data on drug prescriptions from 400 practices in Germany. Also identified were subgroups of the all-patients groups who had received long-term treatment with FEN TDS or BUP TDS and were considered to have similar pain intensity, as they had previously received similar analgesic medication (the identical-cohort groups). Mean prescribed daily doses for the all-patients and identical-cohort groups were calculated based on the distribution of prescribed patch strengths. Because patients could have applied $>1$ patch, mean prescribed daily doses were also calculated based on an assumption of double application when appropriate. Equipotent oral morphine doses were estimated using equipotency ratios of 1:100 for FEN TDS and 1:75 for BUP TDS. The all-patients groups consisted of 2198 patients with non-cancer pain and 2544 patients with cancer pain; the identical-cohort groups consisted of 380 patients with non-cancer pain and 496 patients with cancer pain (529 women, 347 men; mean age, 74 years [range, 25 to 101 years]). Equipotent doses of oral morphine were significantly lower in patients receiving BUP TDS compared with those receiving FEN TDS $(P<0.001)$. In cancer patients, the equipotent oral morphine doses of FEN TDS and BUP TDS were 130.9 to $138.9 \mathrm{mg}$ and 85.2 to $88.8 \mathrm{mg}$, respectively; in non-cancer patients, the corresponding values were 117.0 to $118.3 \mathrm{mg}$ and 80.2 to $80.9 \mathrm{mg}$. Based on these results, an equipotency ratio of 1:110 to 1:115 for BUP TDS would appear to be more appropriate than the proposed ratio of 1:75. The fact that this retrospective analysis conducted in identical cohorts showed lower calculated equipotent oral morphine doses in the BUP TDS groups compared with the FEN TDS groups calls into question the proposed 1:75 ratio for conversion of BUP TDS to equipotent oral morphine doses. Based on the findings of the described study, an equipotency ratio of 1:110 to $1: 115$ may be more appropriate. However, confirmative data from larger (prospective and randomized) trials are needed. The findings of all the previously described studies clearly indicate that the analgesic drug (in this case buprenorphine), its formulation, individual response, and the route of administrations are all variables of fundamental importance in the therapeutic result, and the response to opioids probably does not depend on the pathophysiology of the pain alone, but rather a complex phenomenon linked to individual factors. Additional data on equipotency between BUP TDS and other opioids have also been indirectly investigated in studies on the tolerance development. These studies are detailed below.

\section{Transdermal buprenorphine: analgesic tolerance}

Analgesic tolerance is an important factor to consider when choosing the most effective treatment for the management of chronic pain. The risk of dose escalation is higher with full-opioid agonists such as fentanyl because when they bind to $\mu$-opioid receptors downregulation of these receptors results from the cell surface. Downregulation of opioid receptors does not seem to occur during buprenorphine treatment. ${ }^{20}$

A retrospective data analysis reveals BUP TDS maintains effective pain control in patients with cancer $(n=446)$ and non-cancer pain ( $\mathrm{n}=448)$, for at least 3 months, without the need to increase dose significantly. ${ }^{73}$ Significantly higher increases in mean doses of FEN TDS $(P<0.05)$ were documented compared with BUP TDS, which suggests a higher risk of analgesic tolerance development with fentanyl compared with buprenorphine. These results are supported by a more recent study by Sittl et al. ${ }^{74}$ This retrospective analysis used data from the IMS Disease Analyzer-Mediplus database, which contains patient-related data documented by 400 medical practices in Germany. Data from patients with non-cancer pain $(n=631)$ or cancer pain $(n=605)$ with BUP TDS or FEN TDS for at least 3 months were analyzed. Results 
showed a significantly greater dose stability $(P<0.05)$ in patients, with cancer and non-cancer pain, taking BUP TDS compared with FEN TDS. ${ }^{74}$ A significantly larger proportion of patients receiving BUP TDS had stable dosages over the entire treatment period compared with patients receiving FEN TDS (non-cancer groups: $56.9 \%$ vs $41.6 \%$; cancer groups: $50.0 \%$ vs $26.2 \%$; both $P<0.05$ ). It should be noted, however, that the results of this study should be analyzed with great care. Indeed, data of this database were primarily reflecting the prescription practice of GPs rather than a clinical phenomenon. Therefore this study provides only circumstantial evidence of the development of analgesic tolerance.

\section{Transdermal buprenorphine: clinical safety and cost-effectiveness}

The safety of buprenorphine has been documented in numerous clinical studies, with the incidence of adverse effects, typical of this drug class, being lower than other opioids used in an identical clinical setting. ${ }^{75}$ This is possibly due to buprenorphine's 'bell-shaped' dose-response curve being applicable to the spectrum of adverse events. ${ }^{14}$ The majority of systemic effects occur in the central nervous system and gastrointestinal tract and include nausea, dizziness, and constipation. Randomized trials have shown that local adverse events, resulting from BUP TDS, occur in $<25 \%$ of patients in routine clinical practice. ${ }^{9}$ The relatively slow receptor dissociation of buprenorphine may cause fewer symptoms of opioid withdrawal than morphine following cessation of therapy ${ }^{2}$ and there appears to be a ceiling to its effects on respiratory function. ${ }^{75,76}$ In a recent study by Dahan et $\mathrm{al}^{76}$ the dose-response relationship of intravenous buprenorphine (dose range 0 to $0.6 \mathrm{mg}$ ) was determined in healthy volunteers, and compared to a full $\mu$-opioid receptor agonist with high intrinsic activity, fentanyl (dose range 0 to $0.5 \mathrm{mg}$ ). First, fentanyl, but not buprenorphine, caused immediate respiratory arrest upon infusion at doses greater than $0.3 \mathrm{mg}$, lasting 3 to 8 minutes. Second, when plotting the dose against the time-effect data (expressed as areaunder-the-curve, a measure of the overall respiratory effect of the drug) a linear relationship was shown for fentanyl, but non-linear for buprenorphine with a ceiling at doses of $0.2 \mathrm{mg}$ and greater. These distinctive pharmacodynamic respiratory effects of buprenorphine - lack of apnea after even high doses and the development of ceiling effect on respiratory function - have evident clinical advantages over other opioids such as fentanyl and morphine, contributing to the concept that buprenorphine is exceptionally safe to use. Moreover, data indicate that ceiling of respiratory effect occurs at a much lower dose $(0.1 \mathrm{mg} / \mathrm{kg})$ than the ceiling in analgesic effect ( 1.0 to $3.0 \mathrm{mg} / \mathrm{kg}$ ), which indicates the relative safety of buprenorphine combined with its ability to produce effective analgesia. ${ }^{75,76}$ Finally, in the unlikely event of buprenorphine-induced respiratory depression, the effect can be fully reversed with continuous administration of naloxone ${ }^{77}$ as well as doxapam. ${ }^{78}$

Recently several studies have reviewed or investigated the safety profile of BUP TDS in specific patient populations which are especially vulnerable to drug-induced side effects. As such, a prospective, open-labeled, controlled trial compared the gastrointestinal symptoms of oral sustained-release hydromorphone, FEN TDS and BUP TDS in patients with cancer pain. ${ }^{79}$ Mobility, pain and gastrointestinal symptoms were assessed directly and per selected item on the Eastern Cancer Oncolgy Group (ECOG) and European Organisation for Research and Treatment of Cancer (EORTC) questionnaires, as well as the numeric rating scale (NRS). Only 15\% of patients suffered from constipation. The incidence of stool free periods for more than $72 \mathrm{~h}$ was significantly higher with transdermal opioids (FEN TDS: 22\% and BUP TDS: 21\%) than with oral hydromorphone (2\%). Nausea, consumption of emetics and laxatives did not differ significantly between the 3 treatment groups. However, score for emesis was significantly higher for oral hydromorphone compared to the transdermal opioids.

Furthermore, it should be noted that the previously mentioned large-scale study in cancer patients, ${ }^{55}$ showed a reduced incidence of adverse events in the maintenance phase compared to the run-in period. Indeed, transdermal formulations are expected to reduce adverse events by slowly releasing the drug into the bloodstream and maintaining a steady plasma concentration. Reduced side effects, especially for constipation, were repeatedly reported for transdermal systems and may be related to a bypass of enteral opioid receptors. ${ }^{80}$ The constipation rate in this study was $7.4 \%$, which was comparable to previous results with BUP TDS and lower than FEN TDS or sustained-release morphine (producing rates between 20\% and 44.5\%).

Tassinari et al reviewed the adverse effects of transdermal opioids to long-acting morphine in the treatment of moderate to severe cancer pain. ${ }^{81}$ They identified 4 trials, comparing the safety of FEN TDS and BUP TDS and slow-release oral morphine in 425 patients. A significant difference in favor of transdermal opiates was observed for constipation, and patients' preference. No significant differences were observed for overall adverse effects, 
overall gastrointestinal adverse effects, overall neurologic adverse effects, nausea, somnolence, hypoventilation, trial withdrawal, and changes in opioid treatments. Another prospective trial focused on the gastrointestinal symptoms occurring under opioid therapy. ${ }^{72}$ The purpose of this trial was to evaluate the effect of long-term treatment with oral sustained-release hydromorphone, FEN TDS, and BUP TDS on nausea, emesis, and constipation. Randomly selected outpatients with cancer pain receiving one of the study medications were enrolled in a prospective, open-labeled, controlled trial $(n=174)$. Mobility, pain, and gastrointestinal symptoms were assessed directly and per selected item on the ECOG and EORTC questionnaires and the NRS, and analyzed statistically. Overall, only $15 \%$ of patients suffered from constipation. 59\% took the prescribed laxatives. The incidence of stool free periods $>72$ hours was significantly higher with transdermal opioids (FEN TDS: 22\%; BUP TDS: $21 \%$; oral hydromorphone: $2 \% ; P=0.003$ ). $21 \%$ of patients revealed nausea and emesis. The mean NRS for nausea (FEN TDS:1.3; BUP TDS: 1.2; oral hydromorphone: $1.5 ; P=0.6$ ), the consumption of antiemetics (FEN TDS: 42\%; BUP TDS: 33\%; oral hydromorphone: $36 \%$; $P=0.6$ ) and laxatives (FEN TDS: 53\%; BUP TDS: $66 \%$; oral hydromorphone: $61 \% ; P=0.2$ ) did not differ significantly, in contrast to the score for emesis (FEN TDS: $16 \%$; BUP TDS: $13 \%$; oral hydromorphone: $33 \% ; P=0.02$ ). The authors conclude that gastrointestinal symptoms of cancer-pain patients undergoing an opioid therapy are related to multifactorial causes. Transdermal opioids thereby showed no benefit over oral controlled-release hydromorphone for gastrointestinal symptoms.

Finally, the authors of recent publications on the management of chronic pain in the elderly also concluded that BUP TDS can be used in clinical practice safely and efficaciously for treating chronic pain in elderly. ${ }^{68}$ Despite the very limited available evidence from preclinical and clinical work buprenorphine treatment can, because of its minor immunosuppressive effects, be recommended for use in elderly patients. ${ }^{69}$

Opioids are known to greatly affect the central nervous system. These side effects, such as dizziness and confusion, have been shown to lead to an increased risk of falling, with subsequent fractures and sometimes long-lasting disability. In Germany, a Markov health economic model was developed to investigate the cost-effectiveness of the most commonly used strong opioids, hereby focusing on opioid-related fractures. The most frequently prescribed strength/package-size combinations of these opioids were taken into consideration. The results of this analysis predict that BUP TDS is dominant compared to FEN TDS fentanyl and oxycodone by showing better life years gained/quality adjusted life-years (QALY). ${ }^{82}$ As such, BUP TDS represents a cost-effective treatment option vs morphine in patients with chronic pain. A highly interesting, study assessed the cognitive and psychomotor performance under longterm treatment with BUP TDS in 30 non-cancer patients. ${ }^{83}$ A computerized test battery developed to assess driving ability was used. Attention reaction, visual orientation, motor coordination, and vigilance were evaluated. According to tests that predict driving ability, patients receiving BUP TDS were shown to be non-inferior to the control group. Due to the individual variability of test results, an individual assessment is always recommended.

Effective pain management depends upon balancing the effectiveness of a drug with its side effects. The specific pain management needs of patients varies and is therefore flexible, yet careful dose titration is the best way to achieve balanced pain management. When low-dose patches are not available, cutting BUP TDS patches may offer a practical solution to gradual dose titration and finding the optimal dose for the individual patient. Louis reports 5 case studies in which 3 patients had mixed pain, including neuropathic pain. ${ }^{84}$ Two patients used one half of a $35 \mu \mathrm{g} / \mathrm{h}$ buprenorphine patch and 1 used one-quarter of a $35 \mu \mathrm{g} / \mathrm{h}$ buprenorphine patch, titrated to one $70 \mu \mathrm{g} / \mathrm{h}$ BUP TDS patch at 3 months. Cutting the patches in half did not seem to affect the efficacy of the analgesic treatment in these patients.

Finally, one of the most particular and common adverse events with BUP TDS are site-specific adverse effects. These include erythematous regions around the patch site (approximately 20\% incidence) and pruritus at the patch application site. Of the latter one of the previously described studies reported an incidence of $9.3 \%$ vs $5.1 \%$ after application of placebo patches. ${ }^{67} \mathrm{~A}$ double series of case reports described the problem of allergic contact dermatitis to BUP TDS. ${ }^{85,86}$ Patients developed persistent, pruritic erythematous plaques at the contact sites, with sometimes even generalized skin eruption. ${ }^{86}$ Most of these patients also reacted to transdermal buprenorphine (without the transdermal delivery system), the placebo being negative. This skin irritance seems to be perhaps the most negative clinical finding, and remains often difficult to manage in routine clinical setting. In another study, the skin irritation potential of a single application of FEN TDS and BUP TDS patches was compared in healthy volunteers. ${ }^{87} 46$ healthy 
males and females (mean age [range]: 59.6 [50 to 69] years) with healthy skin received a single dose of both the FEN TDS $25 \mu \mathrm{g} / \mathrm{h}$ patch and the BUP TDS $35 \mu \mathrm{g} / \mathrm{h}$ patch in a randomized order. The incidence and severity of erythema were assessed at various timepoints after patch removal. The results indicate that there was a non-significant trend towards a higher incidence of erythema 60 minutes after patch removal with BUP TDS compared with FEN TDS. The severity of erythema at 60 minutes and the incidence of erythema at 72 hours after patch removal were significantly higher with BUP TDS than with FEN TDS $(P=0.01$ and $22 \%$ vs $4.9 \%, P=0.04$, respectively). In general, the results from the chromametric assessment of treated skin were in agreement. The incidence of topical AEs was lower with FEN TDS than with BUP TDS (1 vs 6 events) and subjects preferred the fentanyl patch and felt it was less noticeable on the skin. The FEN TDS was considered less painful to remove, and, consistent with this, the BUP TDS patch was judged to have better adhesion.

Recently, the pharmacokinetics, analgesic efficacy, and irritancy potential of a new transdermal delivery system of buprenorphine $\left(\right.$ Buprederm ${ }^{\circledR}$ ) were evaluated in rodents. ${ }^{88}$ Interestingly, no skin irritation was demonstrated in rabbits after repeated Buprederm application. This new transdermal delivery system holds great promise to reduce the occurrence of skin irritation, but further clinical studies will need to prove its real-life value. In the mean time, several measures can be taken to prevent the occurrence of such skin irritation or at least reduce its severity. Preemptive treatment of the skin with a transparent by permeable film or topical application of a corticosteroid aerosol can effectively reduce the occurrence and intensity of skin reactions.

\section{Future perspectives: expansion into new applications}

In recent years, with expanding use of the transdermal buprenorphine patches, new challenging areas of clinical application have been identified. One of the most promising applications is the use of the BUP TDS in an intensive care setting. Many of these critically ill patients suffer from prolonged severe pain conditions (eg, post-traumatic pain, critical illness neuropathy, visceral pain syndromes), requiring sedation and intravenous administration of (high doses) of opioids for longer periods of time. This application is often complicated by (rapid) development of opioid-induced hyperalgesia whereby opioid administration results in a lowering of pain threshold, clinically manifest as apparent opioid tolerance, worsening pain, and abnormal pain sensations such as allodynia (for review see). ${ }^{89,90}$ Once opioid-induced hyperalgesia is diagnosed or provisionally considered, treatment strategies could include opioid dose reduction, use of agents with NMDA receptor antagonism, but also opioid rotation. The very specific (multimodal) pharmacological features of buprenorphine render this drug especially interesting for use in this vulnerable patient population. Experience in our center has indicated that treatment with BUP TDS is very useful and well tolerated in criticially ill patients.

Additionally, BUP TDS should be more often considered as a first-line therapeutic option in post-traumatic patients at the start of their (long-term) revalidation. In these cases treatment with buprenorphine patches could be initiated immediately post-operatively, providing the transition from more invasive analgesic treatments (eg, neuraxial or peripheral nerve blocks, PCA pumps) to continuous systemic analgesic therapy. Such treatment with BUP TDS can easily be tailored to the healing process of the patients, with decreasing doses as the patient recovers from the sustained injuries.

\section{Conclusions}

The pharmacological and clinical profiles of buprenorphine have been documented in a growing number of clinical studies, demonstrating buprenorphine's potential effectiveness in the treatment of diverse acute and chronic pain conditions. Buprenorphine shows no relevant analgesic ceiling effect throughout the therapeutic dose range, but indeed has a ceiling effect for respiratory depression. Most notably, buprenorphine seems to be potentially effective in the management of nociceptive pain syndromes as well as neuropathic hyperalgesic states and syndromes characterized by the presence of pronounced central sensitization. In addition, there seems to be no development of tolerance during long-term treatment. Finally, transdermal buprenorphine can be safely used in vulnerable patient populations, such as elderly and patients with renal impairment.

\section{Disclosures}

The authors declare no conflicts of interest.

\section{References}

1. Heel RC, Brogden RN, Speight TM, Avery GS. Buprenorphine: a review of its pharmacological properties and therapeutic efficacy. Drugs. 1979;17:81-110.

2. Johnson RE, Fudala PJ, Payne R. Buprenorphine: considerations for pain management. J Pain Symptom Manage. 2005;29:297-326.

3. Rance MJ, Shillingford JS. The metabolism of phenolic opiates by rat intestine. Xenobiotica. 1977;7:529-536. 
4. Filitz J, Griessinger N, Sittl R, Likar R, Schuttler J, Koppert W. Effects of intermittent hemodialysis on buprenorphine and norbuprenorphine plasma concentrations in chronic pain patients treated with transdermal buprenorphine. Eur J Pain. 2006;10:743-748.

5. Inturrisi CE. Clinical pharmacology of opioids for pain. Clin J Pain. 2002;18:S3-S13.

6. Eisen SA, Miller DK, Woodward RS, Spitznagel E, Przybeck TR. The effect of prescribed daily dose frequency on patient medication compliance. Arch Intern Med. 1990;150:1881-1884.

7. Claxton AJ, Cramer J, Pierce C. A systematic review of the associations between dose regimens and medication compliance. Clin Ther. 2001;23:1296-1310.

8. Richter A, Anton SE, Koch P, Dennett SL. The impact of reducing dose frequency on health outcomes. Clin Ther. 2003;25:2307-2335; discussion 6.

9. Bohme K. Buprenorphine in a transdermal therapeutic system - a new option. Clin Rheumatol. 2002;21 Suppl 1:S13-S16.

10. Budd K. Buprenorphine and the transdermal system: the ideal match in pain management. Int J Clin Pract Suppl. 2003:9-14; discussion $23-24$.

11. Vallerand AH. The use of long-acting opioids in chronic pain management. Nurs Clin North Am. 2003;38:435-445.

12. Kalia YN, Merino V, Guy RH. Transdermal drug delivery. Clinical aspects. Dermatol Clin. 1998;16:289-299.

13. Budd K. High dose buprenorphine for postoperative analgesia. Anaesthesia. 1981;36:900-903.

14. Walsh SL, Preston KL, Stitzer ML, Cone EJ, Bigelow GE. Clinical pharmacology of buprenorphine: ceiling effects at high doses. Clin Pharmacol Ther. 1994;55:569-580.

15. Lutfy K, Cowan A. Buprenorphine: a unique drug with complex pharmacology. Curr Neuropharmacol. 2004;2:395-402.

16. Cowan A. Buprenorphine: new pharmacological aspects. Int J Clin Pract Suppl. 2003:3-8; discussion 23-24.

17. Hans G. Buprenorphine - a review of its role in neuropathic pain. J Opioid Manag. 2007;3:195-206.

18. Faymonville ME, Libbrecht D. [Transdermal buprenorphine: a current overview of pharmacological and clinical data]. Rev Med Liege. 2008;63:671-676

19. Kress HG. Clinical update on the pharmacology, efficacy and safety of transdermal buprenorphine. Eur J Pain. 2009;13:219-230.

20. Cowan A, Lewis JW, Macfarlane IR. Agonist and antagonist properties of buprenorphine, a new antinociceptive agent. Br J Pharmacol. 1977;60:537-545.

21. McCormack K, Prather P, Chapleo C. Some new insights into the effects of opioids in phasic and tonic nociceptive tests. Pain. 1998;78:79-98.

22. Hans G. Buprenorphine - a review of its role in neuropathic pain. J Opioid Manag. 2007;3:195-206.

23. Pick CG, Peter Y, Schreiber S, Weizman R. Pharmacological characterization of buprenorphine, a mixed agonist-antagonist with kappa 3 analgesia. Brain Res. 1997;744:41-46.

24. Schreiber S, Backer MM, Yanai J, Pick CG. The antinociceptive effect of fluvoxamine. Eur Neuropsychopharmacol. 1996;6:281-284.

25. McLaughlin CR, Tao Q, Abood ME. Analysis of the antinociceptive actions of the kappa-opioid agonist enadoline (CI-977) in neonatal and adult rats: comparison to kappa-opioid receptor mRNA ontogeny. Drug Alcohol Depend. 1995;38:261-269.

26. Sanchez JA, Gonoi T, Inagaki N, Katada T, Seino S. Modulation of reconstituted ATP-sensitive $\mathrm{K}(+)$-channels by GTP-binding proteins in a mammalian cell line. $J$ Physiol. 1998;507(Pt 2): 315-324.

27. Wada Y, Yamashita T, Imai K, et al. A region of the sulfonylurea receptor critical for a modulation of ATP-sensitive $\mathrm{K}(+)$ channels by G-protein betagamma-subunits. EMBO J. 2000;19: 4915-4925.

28. Mark MD, Herlitze S. G-protein mediated gating of inward-rectifier K+ channels. Eur J Biochem. 2000;267:5830-5836.
29. Ocana M, Del Pozo E, Barrios M, Baeyens JM. Subgroups among mu-opioid receptor agonists distinguished by ATP-sensitive K+ channel-acting drugs. Br J Pharmacol. 1995;114:1296-1302.

30. Wood JN, Abrahamsen B, Baker MD, et al. Ion channel activities implicated in pathological pain. Novartis Found Symp. 2004;261:32-40; discussion-54.

31. Yang EK, Takimoto K, Hayashi Y, de Groat WC, Yoshimura N. Altered expression of potassium channel subunit mRNA and alpha-dendrotoxin sensitivity of potassium currents in rat dorsal root ganglion neurons after axotomy. Neuroscience. 2004;123:867-874.

32. Bloms-Funke P, Gillen C, Schuettler AJ, Wnendt S. Agonistic effects of the opioid buprenorphine on the nociceptin/OFQ receptor. Peptides. 2000;21:1141-1146.

33. Hawkinson JE, Acosta-Burruel M, Espitia SA. Opioid activity profiles indicate similarities between the nociceptin/orphanin FQ and opioid receptors. Eur J Pharmacol. 2000;389:107-114.

34. Huang P, Kehner GB, Cowan A, Liu-Chen LY. Comparison of pharmacological activities of buprenorphine and norbuprenorphine: norbuprenorphine is a potent opioid agonist. J Pharmacol Exp Ther. 2001;297:688-695.

35. Wnendt S, Kruger T, Janocha E, Hildebrandt D, Englberger W. Agonistic effect of buprenorphine in a nociceptin/OFQ receptor-triggered reporter gene assay. Mol Pharmacol. 1999;56:334-338.

36. Lutfy K, Eitan S, Bryant CD, et al. Buprenorphine-induced antinociception is mediated by mu-opioid receptors and compromised by concomitant activation of opioid receptor-like receptors. $J$ Neurosci. 2003;23:10331-10337.

37. Hentz JG, Valle-Robillart A, Franckhauser J, Froehly S, Dupeyron JP. The use of intrathecal morphine in thoracic anesthesia. J Cardiothorac Anesth. 1989;3:24.

38. Lundborg CN, Nitescu PV, Appelgren LK, Curelaru ID. Progressive systemic sclerosis: intrathecal pain management. Reg Anesth Pain Med. 1999;24:89-93.

39. Nitescu P, Dahm P, Appelgren L, Curelaru I. Continuous infusion of opioid and bupivacaine by externalized intrathecal catheters in long-term treatment of "refractory" nonmalignant pain. Clin J Pain. 1998;14:17-28.

40. Tejwani GA, Rattan AK. The role of spinal opioid receptors in antinociceptive effects produced by intrathecal administration of hydromorphone and buprenorphine in the rat. Anesth Analg. 2002;94:1542-1546.

41. Guirimand F, Chauvin M, Willer JC, Le Bars D. Effects of intrathecal and intracerebroventricular buprenorphine on a C-fiber reflex in the rat. J Pharmacol Exp Ther. 1995;275:629-637.

42. Inagaki Y, Mashimo T, Yoshiya I. Mode and site of analgesic action of epidural buprenorphine in humans. Anesth Analg. 1996;83:530-536.

43. Jadad AR, Moore RA, Carroll D, et al. Assessing the quality of reports of randomized clinical trials: is blinding necessary? Control Clin Trials. 1996;17:1-12.

44. Sittl R, Griessinger N, Likar R. Analgesic efficacy and tolerability of transdermal buprenorphine in patients with inadequately controlled chronic pain related to cancer and other disorders: a multicenter, randomized, double-blind, placebo-controlled trial. Clin Ther. 2003;25:150-168.

45. Sorge J, Sittl R. Transdermal buprenorphine in the treatment of chronic pain: results of a phase III, multicenter, randomized, double-blind, placebo-controlled study. Clin Ther. 2004;26:1808-1820.

46. Likar R, Kayser H, Sittl R. Long-term management of chronic pain with transdermal buprenorphine: a multicenter, open-label, follow-up study in patients from three short-term clinical trials. Clin Ther. 2006;28: 943-952.

47. Griessinger N, Sittl R, Likar R. Transdermal buprenorphine in clinical practice - a post-marketing surveillance study in 13,179 patients. Curr Med Res Opin. 2005;21:1147-1156.

48. Radbruch L, Sabatowski R, Petzke F, Brunsch-Radbruch A, Grond S, Lehmann KA. Transdermal fentanyl for the management of cancer pain: a survey of 1005 patients. Palliat Med. 2001;15:309-321. 
49. Tschirner M, Ritzdorf I, Brunjes R. [Post marketing surveillance study with an analgesic (transdermal buprenorphine patch) in patients with moderate to severe chronic pain]. MMW Fortschr Med. 2008;150 Suppl 3:142-148.

50. Likar R, Lorenz V, Korak-Leiter M, Kager I, Sittl R. Transdermal buprenorphine patches applied in a 4-day regimen versus a 3-day regimen: a single-site, Phase III, randomized, open-label, crossover comparison. Clin Ther. 2007;29:1591-1606.

51. Barutell C, Camba A, Gonzalez-Escalada JR, Rodriguez M. High dose transdermal buprenorphine for moderate to severe pain in spanish pain centres - a retrospective multicenter safety and efficacy study. Pain Pract. 2008;8:355-361.

52. Rodriguez-Lopez M. Transdermal buprenorphine in the treatment of neuropathic pain. Rev Soc Esp Dolor. 2004;11:S11-S21.

53. Penza P, Campanella A, Martini A, et al. Short- and intermediate-term efficacy of buprenorphine TDS in chronic painful neuropathies. J Peripher Nerv Syst. 2008;13:283-288.

54. Likar R, Sittl R. Transdermal buprenorphine for treating nociceptive and neuropathic pain: four case studies. Anesth Analg. 2005;100:781-785.

55. Poulain P, Denier W, Douma J, et al. Efficacy and safety of transdermal buprenorphine: a randomized, placebo-controlled trial in 289 patients with severe cancer pain. J Pain Symptom Manage. 2008;36:117-125.

56. Muriel C; The Opioid Study Group of the Spanish Pain Society. Assessment of buprenorphine transdermal patch in patients with cancer pain. Rev Soc Esp Dolor. 2004;1 Suppl V:41-48.

57. Muriel C, Failde I, Mico JA, Neira M, Sanchez-Magro I. Effectiveness and tolerability of the buprenorphine transdermal system in patients with moderate to severe chronic pain: a multicenter, open-label, uncontrolled, prospective, observational clinical study. Clin Ther. 2005;27:451-462.

58. Attina G, Ruggiero A, Maurizi P, Arlotta A, Chiaretti A, Riccardi R. Transdermal buprenorphine in children with cancer-related pain. Pediatr Blood Cancer. 2009;52:125-127.

59. Pergolizzi JV, Mercadante S, Echaburu AV, et al. The role of transdermal buprenorphine in the treatment of cancer pain: an expert panel consensus. Curr Med Res Opin. 2009 May 11. [Epub ahead of print].

60. Koppert W, Ihmsen H, Korber N, et al. Different profiles of buprenorphine-induced analgesia and antihyperalgesia in a human pain model. Pain. 2005;118:15-22.

61. Mercadante S, Porzio G, Fulfaro F, et al. Switching from transdermal drugs: an observational "N of 1" study of fentanyl and buprenorphine. J Pain Symptom Manage. 2007;34:532-538.

62. Freye E, Anderson-Hillemacher A, Ritzdorf I, Levy JV. Opioid rotation from high-dose morphine to transdermal buprenorphine (Transtec) in chronic pain patients. Pain Pract. 2007;7:123-129.

63. Aurilio C, Pace MC, Pota V, et al. Opioids switching with transdermal systems in chronic cancer pain. J Exp Clin Cancer Res. 2009;28:61

64. Aurilio C, Pace MC, Passavanti MB, et al. Treatment of Ischemic pain in patients suffering from peripheral vasculopathy with transdermal buprenorphine plus epidural morphine with ropivacaine vs epidural morphine with ropivacaine. Pain Pract. 2009;9:105-114.

65. Schutter U, Ritzdorf I, Heckes B. [Treatment of chronic osteoarthritis pain: effectivity and safety of a 7 day matrix patch with a low dose buprenorphine]. MMW Fortschr Med. 2008;150 Suppl 2:96-103.

66. Karlsson M, Berggren AC. Efficacy and safety of low-dose transdermal buprenorphine patches $(5,10$, and $20 \mathrm{microg} / \mathrm{h})$ versus prolongedrelease tramadol tablets $(75,100,150$, and $200 \mathrm{mg})$ in patients with chronic osteoarthritis pain: a 12-week, randomized, open-label, controlled, parallel-group noninferiority study. Clin Ther. 2009;31:503513.

67. Landau CJ, Carr WD, Razzetti AJ, Sessler NE, Munera C, Ripa SR. Buprenorphine transdermal delivery system in adults with persistent noncancer-related pain syndromes who require opioid therapy: a multicenter, 5-week run-in and randomized, double-blind maintenanceof-analgesia study. Clin Ther. 2007;29:2179-2193.
68. Likar R, Vadlau EM, Breschan C, Kager I, Korak-Leiter M, Ziervogel G. Comparable analgesic efficacy of transdermal buprenorphine in patients over and under 65 years of age. Clin J Pain. 2008;24:536-543.

69. Pergolizzi J, Boger RH, Budd K, et al. Opioids and the management of chronic severe pain in the elderly: consensus statement of an International Expert Panel with focus on the six clinically most often used World Health Organization step III opioids (buprenorphine, fentanyl, hydromorphone, methadone, morphine, oxycodone). Pain Pract. 2008;8:287-313

70. Vadivelu N, Hines RL. Management of chronic pain in the elderly: focus on transdermal buprenorphine. Clin Interv Aging. 2008;3:421-430.

71. Mercadante S, Casuccio A, Tirelli W, Giarratano A. Equipotent doses to switch from high doses of opioids to transdermal buprenorphine. Support Care Cancer. 2009;17:715-718.

72. Wirz S, Wittmann M, Schenk M, et al. Gastrointestinal symptoms under opioid therapy: A prospective comparison of oral sustained-release hydromorphone, transdermal fentanyl, and transdermal buprenorphine. Eur J Pain. 2009;13(7):737-743.

73. Sittl R, Likar R, Nautrup BP. Equipotent doses of transdermal fentanyl and transdermal buprenorphine in patients with cancer and noncancer pain: results of a retrospective cohort study. Clin Ther. 2005;27:225-237.

74. Sittl R, Nuijten M, Nautrup BP. Patterns of dosage changes with transdermal buprenorphine and transdermal fentanyl for the treatment of noncancer and cancer pain: a retrospective data analysis in Germany. Clin Ther. 2006;28:1144-1154.

75. Likar R. Transdermal buprenorphine in the management of persistent pain - safety aspects. Ther Clin Risk Manag. 2006;2:115-125.

76. Dahan A. Opioid-induced respiratory effects: new data on buprenorphine. Palliat Med. 2006;20 Suppl 1:S3-S8.

77. van Dorp E, Yassen A, Sarton E, et al. Naloxone reversal of buprenorphine-induced respiratory depression. Anesthesiology. 2006;105:51-57.

78. Orwin JM. The effect of doxapram on buprenorphine induced respiratory depression. Acta Anaesthesiol Belg. 1977;28:93-106.

79. Greco MT, Deandrea S, Corli O, Montanari M, Caraceni A, Apolone G. [Effects of transdermal buprenorphine in cancer patients. Results from the Cancer Pain Outcome Research (CPOR) Study Group]. Recenti Prog Med. 2008;99:538-551.

80. Radbruch L, Sabatowski R, Loick G, et al. Constipation and the use of laxatives: a comparison between transdermal fentanyl and oral morphine. Palliat Med. 2000;14:111-119.

81. Tassinari D, Sartori S, Tamburini E, et al. Adverse effects of transdermal opiates treating moderate-severe cancer pain in comparison to long-acting morphine: a meta-analysis and systematic review of the literature. J Palliat Med. 2008;11:492-501.

82. Hass B, Lungershausen J, Hertel N, Poulsen Nautrup B, Kotowa W, Liedgens $\mathrm{H}$. Cost-effectiveness of strong opioids focussing on the long-term effects of opioid-related fractures: a model approach. Eur $J$ Health Econ. 2009;10(3):309-321.

83. Dagtekin O, Gerbershagen HJ, Wagner W, Petzke F, Radbruch L, Sabatowski R. Assessing cognitive and psychomotor performance under long-term treatment with transdermal buprenorphine in chronic noncancer pain patients. Anesth Analg. 2007;105:1442-1448.

84. Louis F. Transdermal buprenorphine in pain management-experiences from clinical practice: Five case studies. Int J Clin Pract. 2006;60:1330-1334.

85. Perez-Perez L, Cabanillas M, Loureiro M, Fernandez-Redondo V, Labandeira J, Toribio J. Allergic contact dermatitis due to transdermal buprenorphine. Contact Dermatitis. 2008;58:310-312.

86. Vander Hulst K, Parera Amer E, Jacobs C, et al. Allergic contact dermatitis from transdermal buprenorphine. Contact Dermatitis. 2008;59:366-369.

87. Schmid-Grendelmeier P, Pokorny R, Gasser UE, Richarz U. A comparison of the skin irritation potential of transdermal fentanyl versus transdermal buprenorphine in middle-aged to elderly healthy volunteers. Curr Med Res Opin. 2006;22:501-509. 
88. Park I, Kim D, Song J, et al. Buprederm, a new transdermal delivery system of buprenorphine: pharmacokinetic, efficacy and skin irritancy studies. Pharm Res. 2008;25:1052-1062.

89. Mitra S. Opioid-induced hyperalgesia: pathophysiology and clinical implications. J Opioid Manag. 2008;4:123-130.
90. Chu LF, Angst MS, Clark D. Opioid-induced hyperalgesia in humans: molecular mechanisms and clinical considerations. Clin J Pain. 2008;24:479-496.

\section{Publish your work in this journal}

The Journal of Pain Research is an international, peer-reviewed, open access, online journal that welcomes laboratory and clinical findings in the fields of pain research and the prevention and management of pain. Original research, reviews, symposium reports, hypothesis formation and commentaries are all considered for publication.

\section{Dovepress}

The manuscript management system is completely online and includes a very quick and fair peer-review system, which is all easy to use. Visit http://www.dovepress.com/testimonials.php to read real quotes from published authors. 